\title{
Look What I Did Today: A Case Study on the Introduction of Social Networking to an Early Childhood Classroom
}

\author{
Donna E. Karno and Bethany W. Bilodeau \\ Department of Early Childhood Education, University of Maine at Farmington, Farmington Maine, United \\ States \\ Email: donna.karno@maine.edu
}

\begin{abstract}
Formal and informal methods of communication between parents and teachers are considered critical to high quality early childhood classrooms that use developmentally appropriate practice (Clarke-Stewart \& Allhusen, 2005; Copple \& Bredekamp, 2009). With the increasing use of social media, communication methods are undergoing significant change throughout society (PewResearch, 2014b). This research explored the introduction of a secure social network site to a preschool classroom, and the impact the social network site had on teacher, child, and parent communication. The study found that for those parents who used the social network site, there was a deeper understanding of "what went on" in the classroom. Parents who participated in the social network site also reported sharing the pictures and videos with their children, and aiding in parentchild discussion about the class. For non-participating parents, there was a decrease in their perception that teachers were providing detail and information regarding their child's day. For the participating and non-participating parents, there was no increase in collaboration levels. The social network site succeeded in bringing the classroom to parents in a manner not previously possible.
\end{abstract}

Keywords: Early childhood, parent communication, technology.

\section{Introduction}

Parent - teacher collaboration and communication is a critical component to quality early childhood education (Clarke-Stewart \& Allhusen, 2005). Using Copple and Bredekamp's (2009) guidelines on quality early education and developmentally appropriate practice, collaboration and communication embody specific qualities. These qualities include: a) welcoming classrooms and inviting parent participation in the program; b) open dialogue; and c) frequent and positive bi-directional communication (Copple \& Bredekamp, 2009). The current prevalence of social media suggests that it might be an effective means of communication in an early childhood education setting. The use of a social media site might allow communication and collaboration to be more inviting and open to a new generation of parents. Research into parent-teacher communication and collaboration is not a new topic, but currently does not include the use of social media. Traditionally, parent - teacher communication includes multiple formal and informal methods to ensure that parents feel connected and involved in the care and education of their children. Strong communication encourages collaboration between parents and teachers aiding in the development of children emotionally, physically, socially, and academically. However, methods of communication are undergoing a radical change as the use of social media increases (Duggan \& Smith, 2014). A dearth of research exists regarding social media (and specifically social networks), suggesting an opportunity to illuminate and enrich the understanding of social networking as a means of communication in early childhood classrooms.

Research has found that communication in early education includes empowering parents to aid in a sense of control over the child's care, creating a dialogue with parents, and ensuring that the classroom is visible to parents (Greenman, 1993; Pelo, 2002). Ghazvini and Readdick (1994) discovered in a study that analyzed parent perception of teacher contact, that high frequency of parent-teacher contact positively correlated with better child care quality. They also found that parents could be separated into three different categories regarding their perception of information about their child's daycare center: a) parents who felt they had enough information, b) parents who felt they had enough information if they 
asked, and c) those who felt they did not receive enough information. Parents who fell into the last category reported that the caregivers were too few or too busy to provide information. Roughly onethird of parents fell into each category.

Most parents report high levels of satisfaction with their child's daycare partnerships, but indicate that they lack knowledge regarding what happens in their child's classroom (Clarke-Stewart \& Allhusen, 2005). In a study conducted by Schpancer et al. (2002), the lack of knowledge was found to be partly due to the failure of the daycare center to successfully find effective protocols for information exchange. Centers do not consistently communicate what is happening in the classroom, and introducing parents to a new understanding of classroom "goings-on" to parents is challenging for daycare directors and teachers. Barriers to successful communication include a myriad of factors. One study (Coleman, 1991) reported family structure and work schedules as barriers. Although parents in the Ghazvini and Readdick (1994) study reported caregiver-based barriers, Reedy and McGrath (2010) reported parentbased barriers. Parents wanted as much information about their child's day as possible, but were too busy attending to their children at pickup for effective communication. In addition, parents reported misplacing written communication before they had an opportunity to read the material.

For the issue of collaboration, one argument that emerges within the literature, is whether parent involvement exerts a positive influence over a child's academic outcome. Previous research exploring the relationship between parent involvement and academic outcomes for the child is mixed (Fantuzzo, McWayne, \& Perry, 2004; Hughes \& Macnaughton, 2000; Okpala, Okpala \& Smith, 2001). El Nokali, Bachman, and Votruba-Drzal examined data from the National Institute of Child Health and Human Development (NICHD) Study of Early Childcare and Youth Development (SECCYD) at 1st, 3rd, and 5 th grades, and found that parent involvement did not predict improved child academic outcomes. In a meta-analysis, Fan and Chen (2001) reported moderate associations between preschool and kindergarten parent involvement and several academic-related issues including child achievement motivation and task persistence. One study that looked at academic outcomes and teacher-rated family involvement (RimmKauffman, Pianta, Cox, \& Bradley, 2003) found that positive family attitudes towards school was a more consistent predictor of better outcomes than family involvement, as reported by the kindergarten teachers.

Traditional methods of communication including conversation at pick-up and drop-off, newsletters, and formal conferences are effective, but younger parents rely heavily on social media as a major means of communication. The PewResearch Internet Project (2014a) reports that $14 \%$ of American adults do not go online, and only $8 \%$ of these offline adults are 49 years and younger. Of the $87 \%$ of American adults who do go online, $93 \%$ are 30-49 years old and 97\% 18-29 years old. And $73 \%$ of adults online use some kind of social network site (PewResearch, 2014b). The heavy use of social networks implies that adopting one for parent-teacher communication in early childhood has the potential to "bring the classroom" to parents in a relevant and effective way.

Social networking can conceivably bring the classroom into the home of the child, allowing parents to stay informed about the educational experiences of their child (Nelms, 2002; Tobolka, 2006). Families can view pictures and videos of classroom activities with the child, and then post comments on the site. Teachers and parents (and other family members) have the opportunity to engage in dialogue concerning the classroom, within the social network site. Thus the social network opens up a new venue for parents to communicate with each other, children in classroom, their own children, and the classroom teachers. Without a social network, these types of interactions among so many interested individuals are limited to face-to-face meetings between individuals or as a group.

\subsection{Theoretical Foundation}

Effective collaboration and communication between the school and parents requires a dynamism and fluidity between and within the ecological environments of the individual that is difficult to fully portray without the perspective of interactions within the child's ecological system. Uri Bronfenbrenner (1977; 1979) successfully captured multi-level interactions with his ecological system model. Social networking provides the parent an opportunity to view the child in the microsystem as she inhabits the classroom. In addition, a social network invites parents into the child's mesosystem as interactions between multiple microsystems occur during the child's day. 
In this study, the child exists in the microsystem of the preschool and home. A shift to the mesosystem occurs when the on-going activity of the child becomes meaningful to others and therefore is no longer isolated to the individual child (Brofenbrenner, 1979). The Internet through social media introduces a significant change in how the microsystem, mesosystem, and exosystem interact. Social media is a part of the exosystem, but it resides within the mesosystem as individuals use it to contact one another. Specifically, the social network site becomes an indirect linkage for intersetting communication within the child's ecological system, presenting the opportunity to create intersetting knowledge between parents, children, and teachers relating to the classroom.

This exploratory study introduced Kinfish, a secure social network site into a full-day preschool program. The research focus involves four main questions:

- Will parents join a social network site, and if so to what extent will they participate

- Does utilizing a social network site aid parents in understanding their child's day

- For participating and non-participating parents, in what ways (if at all) does the social network site impact teacher-parent communication

- In what ways will participating parents use a social network site with their children

In broader theoretical context, does social networking between parents and teachers qualitatively expand communication and understanding? Does intersetting communication create the possibility for intersetting knowledge that differs from traditional forms of communication between parents, teachers, and children?

\section{Methods}

A qualitative, exploratory case study design was selected due to the recent addition of using social networking for parent communication in early childhood settings. This case study documents parental perceptions and use of a social network site in their child's school for the first time. The data collection involved surveys, parent interviews, analytics from the selected social network site Kinfish, and analysis of the postings from the Kinfish site.

The primary concern in choosing a social media site included privacy for children, families, and the participating school. The site had to be secure and available only to participating families. Teachers were concerned with confidentiality. Additionally, the site needed to be user friendly for staff and parents and accessible to all. Another main desire was that the site includes photos and video. This was necessary for the inclusion of preschool children in the communication process since they were not able to read and write.

Kinfish was selected as a possibility because of its emphasis on security and the protection of its primary audience base that is children. The format of the site allowed for primarily image based communication. The site was selected upon the offer of collaboration extended by app creators.

\subsection{Participants}

The preschool setting was a NAEYC accredited lab school of a small public university located in the Northeast. The preschool is open to all members of the community, and there are two separate programs within the building. This study occurred in the full day program, which includes 20 families. Of the 20 families, 18 children, 16 parents, and three lead teachers participated in the research. The ethnic composition of the families was European American. The children ranged in age from 2.5 to 5 years. The total years of teaching experience among the three teacher participants ranged from 15 to 30 . The ethnic background of the teachers was European American. One of the lead teachers acted as administrator of the social network site Kinfish. This teacher was responsible for posting of videos and pictures, together with adding comments to the site.

\subsection{Design and Instruments}

The survey included Likert scale and open-ended questions for parents to complete. The Likert scale ranged from 1 (never) to 5 (always). One question asked participating parents how often they visited Kinfish, with an answer ranging from 1 (more than twice a week) to 5 (never). The surveys were 
distributed two times during the academic school year. The first distribution occurred in September at the first parent meeting. Before the parent meeting, parents were given a letter of introduction explaining the Kinfish site together with child and parent permission forms. The letter of introduction was designed to answer basic questions, including the security and confidentiality of the site, as a way to inform parents regarding this new method of communication. Sixteen parents completed the first survey. The surveys were re-distributed to the parents in May. Two parents dropped out, with fourteen surveys completed and returned in May. Three of the fourteen parents did not join the social network site. All fourteen parents consented to the posting of their children's pictures and photos.

The Likert scale survey questions in the first survey focused on parent perceptions regarding the quality and level of communication, understanding of the classroom, and satisfaction with teacher collaboration using traditional parent/teacher communication. The open ended questions involved parent perceptions on how to promote effective teacher-parent collaboration, how they discuss the school day with their child, and how they used the Kinfish site, if at all. The second survey used the same Likert scale questions, but the open-ended questions included a greater focus on how parents used Kinfish with and without their children.

The lead teacher/Kinfish administrator maintained a journal during the study, recording comments made by parents and children involving Kinfish. These comments included what children and parents said about visiting Kinfish at home, parent comments on specific postings, and child comments on being photographed or what they found interesting when they visited the Kinfish site. The journal also included the teacher's thoughts and perceptions of how using Kinfish was changing her level of communication with families.

Comments from parents and children came from informal conversations. These were gathered during other forms of communication such as drop off/pick up and parent-teacher conferences. Additionally, children commented on Kinfish use during the school day. Children's comments were more frequent from children who used the media often at home. Children expressed pleasure at the ability to share their day with parents at home. Children became less attached to their products (ex. block structures) when they could capture it with photography and show parents later. Kinfish use became progressively more a part of the classroom structure as the year went on including frequent comments such as "could you take a picture so my Mom can see this on Kinfish?"

The Kinfish web designers provided the researchers with parent site visitation analytics. The analytics indicated user increase from September to May. The total number of group members totalled 21 with 1.8 views per day in May. Daily site parent visitation peaked in December with 6.67 views per person.

\subsection{Data Analyses}

The open-ended survey questions were coded by finding common word themes that appeared in the parent responses. Since the Likert scale responses recorded when parents were first introduced to Kinfish in September, and then at the latter part of the school year in May, change over time was introduced to the analysis. The ability to review parent response to the Kinfish posting from the beginning of the study, allowed the researchers an additional method for triangulation of information.

\section{$3 \quad$ Results}

\subsection{Parent-teacher Communication}

In September, the fourteen parents reported medium to high levels that teachers provided information and details regarding their child's day in school. Parents responded that they sometimes knew what happened during their child's school day. When parents were surveyed in May, responses between the groups of parents participating and not participating in Kinfish altered. Table 1 shows the difference in parent perceptions between the two groups of parents. For the non-participating parents, there was a decrease in the perception that teachers were providing information regarding their child's school activities. There was also a slight decrease in these parents perception that teachers provided details regarding their child's school activities, and knowledge of what happens during the school day. The three non-participating members did not provide written clarification of their responses. 
Table 1. Mean Parent Perception of Teacher Communication

\begin{tabular}{|c|c|c|c|c|c|c|c|c|}
\hline & \multicolumn{4}{|c|}{$\begin{array}{l}\text { Participating } \\
\quad(n=11)\end{array}$} & \multicolumn{4}{|c|}{$\begin{array}{l}\text { Non-Participating } \\
\qquad(n=3)\end{array}$} \\
\hline & \multicolumn{2}{|c|}{ September } & \multicolumn{2}{|c|}{ May } & \multicolumn{2}{|c|}{ September } & \multicolumn{2}{|c|}{ May } \\
\hline & $M$ & $S D$ & $M$ & $S D$ & $M$ & $S D$ & $M$ & $S D$ \\
\hline $\begin{array}{c}\text { Teacher } \\
\text { Provides } \\
\text { Information }\end{array}$ & 3.45 & 8.20 & 3.91 & .831 & 4.00 & 1.00 & 2.67 & .577 \\
\hline $\begin{array}{c}\text { Teacher } \\
\text { Provides Detail }\end{array}$ & 3.00 & 1.00 & 3.73 & 1.01 & 3.00 & 1.00 & 2.67 & .577 \\
\hline $\begin{array}{c}\text { Knows What } \\
\text { Happens } \\
\text { During Day }\end{array}$ & 3.09 & .539 & 3.91 & .831 & 3.33 & .577 & 3.00 & 1.00 \\
\hline Frequency of Visits & 3.27 & 1.35 & 2.73 & 1.27 & NA & NA & NA & NA \\
\hline
\end{tabular}

Note: Frequency of visits is scaled 1 (more than 2 times a week) to 5 (do not visit); all other scales ranges are 1 (never) to 5 (always).

Participating parents reported an opposite perception - these parents perceived that teachers provided more frequent information and details regarding their child's school activities from September to May. In their written responses, parents indicated finding the photographs and videos helpful in better understanding what happens in their child's classroom during the day. One parent expressed it as being "able to see exactly what the activities look like and how the children participate". Another parent wrote that it helped her "see my children in relation to their classmates". One parent stated that even if he was not able to talk to the teachers that day, he could still see what happened in the classroom.

Table 2: Mean parent responses to collaboration and participation

\begin{tabular}{|c|c|c|c|c|c|c|c|c|}
\hline & \multicolumn{4}{|c|}{$\begin{array}{l}\text { Participating } \\
\quad(n=11)\end{array}$} & \multicolumn{4}{|c|}{$\begin{array}{l}\text { Non-Participating } \\
\qquad(n=3)\end{array}$} \\
\hline & \multicolumn{2}{|c|}{ September } & \multicolumn{2}{|c|}{ May } & \multicolumn{2}{|c|}{ September } & \multicolumn{2}{|c|}{ May } \\
\hline & $M$ & $S D$ & $M$ & $S D$ & $M$ & $S D$ & $M$ & $S D$ \\
\hline $\begin{array}{l}\text { Ability to } \\
\text { Participate }\end{array}$ & 2.81 & .750 & 3.18 & 1.08 & 3.67 & 1.52 & 2.33 & 1.15 \\
\hline $\begin{array}{c}\text { Satisfaction witl } \\
\text { Collaboration }\end{array}$ & 3.18 & 1.08 & 3.90 & .943 & 3.67 & .577 & 4.00 & 1.73 \\
\hline $\begin{array}{c}\text { Would Like to } \\
\text { Collaborate } \\
\text { More }\end{array}$ & 4.09 & 1.22 & 3.91 & .944 & 4.33 & .577 & 3.33 & .577 \\
\hline
\end{tabular}

*Note: Scale ratings ranges are 1 (never) to 5 (always)

The perception that teachers provided details and information regarding their child's school activities was related to the frequency of Kinfish visits during the week/month. As parents were enrolling and becoming familiar with Kinfish, the average parent visited Kinfish on a weekly basis. By May, parents 
were visiting more frequently. Simultaneous to this increase in visits to the site in May, parents reported that teachers provided more information and details regarding their child's school activities (Table 2).

\subsection{Parent-child Communication}

Parents generally responded that their child sometimes provides details regarding school activities. As Table 1 indicates, this perception did not experience much change from September to May. Parents reported most discussions with their child about the school day occurred on the drive home or at dinner. Parents used a variety of sources as prompts for discussion: the classroom communication board, Kinfish postings, and asking specific questions (i.e. projects being worked on). Seven of the eleven participating parents reported viewing the Kinfish photos and videos with their children. These parents reported asking their children about what was happening in the postings. The remaining four parents reported viewing the site without their children.

When asked what types of postings were their favorite, parents responded with a variety of answers. Postings that focused on the activities and products with their child were most frequently cited, particularly new activities/projects from that week. Parents also mentioned enjoying postings that included social interaction between the children. One parent remarked that pictures involving emotions and actions were favorite postings.

These feelings were reflected in the types of postings parents were likely to comment online. Parents were most likely to provide comments and feedback on photos of activities that they had heard about at home, activities that were out of the ordinary (experiments, elaborate art projects, or child directed long term projects), or special events such as field trips or guest speakers. Comments were positive in nature and often highlighted parent pleasure in the opportunities provided for their children. One parent responded "Thanks for all you do for our kiddos! I'm always so impressed with the variety of activities! Fun!"

Despite parent's positive feedback, responses were slow as parents became familiar with the new method of communication. To promote interaction and discussion, teachers posed a question that corresponded to a photo or series of photos. For example, as children experimented with ingredients to form mortar for building with bricks, the teachers asked parents what they thought their children might have used in the successful mixture. Parents guessed ingredients such as peanut butter. This promoted discussion between parents and children as well as allowing both parties to feel more connected to what happens within the classroom during the day.

\subsection{Parent Collaboration}

Parent collaboration was explored three ways: a) sense of ability to participate in child's school learning, b) satisfaction with level of collaboration regarding child's education, and c) desire to collaborate more regarding child's education. Non-participating parents recorded a decrease in ability to participate in their child's learning from September to May. This set of parents also indicated a decrease in interest to collaborate more regarding their child's education from September to May. However, these parents showed an increase in satisfaction with the level of collaboration. Table 2 illustrates that participating parents responded with different perceptions. These parents indicated a slight increase in ability to participate in child's learning from September to May, and no change in their interest to collaborate more regarding their child's education. Satisfaction with existing collaboration increased from September to May for participating parents.

\section{Discussion}

The first question regarding whether parents would participate in a social network was answered with a firm yes. Only three parents did not participate in the Kinfish site. The site analytics supports this conclusion with data indicating that participation expanded to 21 group members. The level of parent participation on the site was mixed. The teachers hoped that parents would participate regularly on the site through the posting of comments. Despite this anticipated outcome, parents' comments were few. Both analytics and parent report showed that while parents were viewing the site frequently, they did 
not know what to say. Teachers were disappointed with this result and hoped to increase communication in the future.

One of the striking results of this study concerned how parents indicated that visiting Kinfish aided in deepening their understanding of their child's day and what happened in the classroom. Kinfish allowed parents to view classroom activities and interactions in a manner not previously possible. In their comments, parents often remarked at the insight they gained into the classroom learning. Perhaps for the first time, parents "entered" the classroom and saw how children participate and learn on a consistent basis. This is how social media became an indirect link between teachers, children and participating parents, and resulted in intersetting knowledge relating to the classroom. This is qualitatively different from knowledge gained through more traditional forms of communication. For example, when parents view their child's work they are unable to see the learning process. Parents felt that their understanding of the learning process significantly increased.

It is difficult to determine how the use of Kinfish impacted parent-teacher communication for the nonparticipating parents. These parents responded with less of a belief that teachers were providing information and details regarding their child's activities. In fact, the non-participating parents were generally less likely to respond with a strong positive sense of communication. Interestingly, these parents indicated high levels of satisfaction regarding their collaboration with their child's education. This study did not ask parents to define collaboration, leaving an incomplete understanding for this response. Based on these results, satisfaction with collaboration is not strongly related to levels of communication.

Participating parents did believe that teachers more consistently provided information and details when surveyed in May. This group of parents also had an increase in their knowing what happened during their child's school day. Simultaneous to this, parents visited the Kinfish site more frequently and in greater numbers. Visiting the Kinfish site allowed parents a greater depth of understanding regarding their child's day and had a positive impact on teacher-parent communication. This result conforms to research on parent-teacher communication (Clarke-Stewart \& Allhusen, 2005; Schpancer et al., 2002). Parents are generally satisfied with their daycare partnerships, but feel that they lack knowledge regarding what occurs to their children during the day. Added to this, parents experience barriers to effective communication with teachers that take place during drop-off and pick-up (Reedy \& McGrath, 2010). The parents in this study who participated in Kinfish responded how much more they found out about what "goes on at the school" by visiting the social network site. The non-participating parents did not have the same sense of better communication with the teachers.

The issue of whether participating parents shared the social network site with their children was mixed. Three parents reported not sharing the site with their children, although they discussed the posting with their children. These three parents did not view Kinfish with their children. The remaining eight parents reported viewing the pictures and videos with their children, most frequently at bedtime. Parents used viewing Kinfish at bedtime as an opportunity to review the day with their child. One parent wrote that her son did not "necessarily talk about the pictures, but enjoyed seeing his friends in the pictures". The Kinfish site added a different type of opportunity for the parents to review the school day with their children.

The results from this case study confirm that using a social network site can create qualitatively new knowledge for parents regarding their child's school experience. Traditional forms of communication are effective in promoting strong teacher-parent relationships, this research suggests that a social network is able to bring depth to how parents and teachers communicate. Kinfish made the classroom "visible" to parents (Greenman, 1993; Pelo, 2002). The social network succeeded in creating intersetting knowledge that qualitatively differed from what participating parents experienced without its use.

Parent collaboration did not increase with the introduction of Kinfish. The lead teachers anticipated using Kinfish would result in increased collaboration. Non-participating and participating parents remained satisfied with their level of collaboration. It is interesting that from September to May, neither parent group expressed a desire for greater collaboration. One parent wrote "I would if I had the time", a response which might have been generally the case. As the school year progressed, parents may have simply become busier.

The small number of participants limited this study. It is difficult to generalize based on three nonparticipating and eleven participating parents. In addition, the parents were of a European-American ethnicity. Future studies are needed to address social media use in ethnically diverse settings. But the 
study offers insight on how social networking can be used to enhance and extend parent-teacher communication. These results pose ideas regarding how a social network in a preschool can impact parent-child communication at home. Further research involving the differences discovered between the participating and non-participating parents is needed. It would be detrimental to communication if a social network site made any parent feel left out. Another additional area for research is the effectiveness of various types of postings in increasing parent understanding of the classroom.

This study focused on using social media, specifically a social network site, in a preschool setting as new means of communication. This study is not asserting that the use of a social network site is appropriate in all settings, but that as a generation of parents who personally use social media on a daily basis begin to enroll children in preschool, the adoption of social networking is not inappropriate. In fact, using the social network site allows parents into the classroom in a way not previously possible. It is not just the posting of pictures and videos, but also the ability of families to post comments on the site and for parents to share the site with their children. This adds a new dimension to communication between parents, children, and teachers in early childhood settings.

\section{References}

1. Bronfenbrenner, U. (1977). Toward an Experimental Ecology of Human Development. American Psychologist, 513-531.

2. Bronfenbrenner, U. (1979). The Ecology of Human Development. Cambridge MA: Harvard University Press.

3. Clarke-Stewart, A. \& Allhusen, V. D. (2005). What we know about childcare. Cambridge, MA: Harvard University Press.

4. Coleman, M. (1991). Planning for parent participation in schools for young children. ERIC Digest 342463.

5. Copple, C., \& Bredekamp, S. (Eds.) (2009). Developmentally appropriate practice (3rd Edition). Washington, DC: NAEYC

6. Duggan, M. \& Smith, A. (January, 2014). Social media update 2013. Available at http://www.pewinternet.org/2013/12/30/social-media-update-2013/.

7. El Nokali, N. E., Bachman, H., and Votruba-Drzal, E. (2010). Parent involvement and children's academic and social development in elementary school. Child Development, 81, 988-1005.

8. Fan, X., \& Chen, M. (2001). Parental involvement and students' academic achievement: A meta-analysis. Educational Psychology Review, 13, 1-22.

9. Fantuzzo, J., McWayne, C., \& Perry, M. A. (2004). Multiple dimensions of family involvement and their relations to behavioral and learning competencies for urban, low-income children. School Psychology Review, 33, 467-480.

10.Ghazvini, A., \& Readdick, C. (1994). Parent-caregiver communication and quality of care in diverse child care settings. Early Childhood Research Quarterly, 9, 207-222.

11.Greenman, J. (1993). Places for childhoods include parents, too. Childcare Exchange, 3, 11-13.

12.Hughes, P., and Macnaughton, G. (2000). Consensus, Dissensus or Community: the politics of parent involvement in early childhood education. Contemporary Issues in Early Childhood, 1(3), 241-258.

13.Nelms, E. (2002). The effects of teacher-created web page on parent communication: An action research study. Action Research Exchange 1(2), n.p.

14.Okpola, C. O., Okpala, A. O., \& Smith, F. E. (2001). Parental involvement, instructional expenditures, family socioeconomic attributes and student achievement. Journal of Educational Research, 95, 110-115.

15.PewResearch Internet Project. (2014a). Offline Adults. Available at http://www.pewinternet.org/data-trend/internet-use/offline-adults/

16.PewResearch Internet Project (2014b). Social networking fact sheet. Available at http://www.pewinternet.org/fact-sheets/social-networking-fact-sheet/

17.Pelo A. (2002). From border to bridges. Childcare Exchange, 11, 38-41.

18.Reedy, C., \& McGrath, W. (2010). Can you hear me now? Staff-parent communication in child care centers. Early Child Development And Care, 180(3), 347-357. doi:10.1080/03004430801908418

19.Rimm-Kaufman, S. E., Pianta, R. C., Cox, M. J., \& Bradley, R. H. (2003). Teacher-rated family involvement and children's social and academic outcomes in kindergarten. Early Education and Development, 14, 179-198.

20.Shpancer, N., Bowden, J., Ferrell, M., Pavlik, S., Robinson, M., Schwind, J., Volpe, E., Williams, L., \& Young, J. (2002). The gap: Parental knowledge about day care. Early Child Development and Care, 172, 635-642. 
21.Tobolka, D. (2006). Connecting teachers and parents through the Internet. Tech Directions, 66(5), 24-26. 